\title{
PENGARUH LINGKUNGAN KERJA \& STRESS KERJA TERHADAP KINERJA KARYAWAN PT. DWI MULYA JAYA MOJOKERTO
}

\author{
Jaeni Siti Qomaroh Jaenun Musolikah¹, M. Munir Rachman², Suharyanto³ \\ Universitas PGRI Adi Buana Surabaya1,2 \\ jaeniqomaroh@gmail.com
}

\begin{abstract}
ABSTRAK
Dijelaskan riset ini menganalisa lingkungan kerja serta stress kerja karyawan PT. Dwi Mulya Jaya Mojokerto terhadap kinerja karyawan. Riset ini memakai pendekatan kuantitatif deskriptif. Adapun populasi riset ini yakni seluruh karyawan PT. Dwi Mulya Jaya Mojokerto sejumlah 76 karyawan. Teknik sampel memakai sampling jenuh. Didapatkan hasil riset thitung $X 14,338$ serta sig. ,010<,05. X2 4,916 serta sig. ,023<,05 serta uji bersamaan 37,075 serta sig., $000<, 05$. Artinya telah terbukti adanya pengaruh secara terpisah serta bersamaan variabel bebas terhadap variabel terikat.
\end{abstract}

Kata kunci: Lingkungan kerja, stress kerja \& kinera karyawan.

\section{ABSTRACT}

This research explained analyzing the work environment and work stress of PT. Dwi Mulya Jaya Mojokerto on employee performance. This research uses a descriptive quantitative approach. The research population is all employees of PT. Dwi Mulya Jaya Mojokerto totaling 76 employees. The sampling technique uses saturated sampling. Obtained results of tcount $X 14,338$ and sig. , $010<, 05 . X 2$ 4,916 and sig. , $023<, 05$ and 37.075 concurrent tests and sig. 000, <05. This means that it has been proven that there is an effect of separate and concurrent independent variables on the dependent variable.

Keyword: Work environment, work stress \& employee performance. 


\section{PENDAHULUAN}

\section{Latar Belakang}

Setiap organisasi ataupun perusahaan pasti memiliki tujuan untuk memperoleh laba atau profit semaksimal mungkin, hal ini dikarenakan visi-misi perusahaan yang akan terus mendorong perusahaan untuk mencapai target perusahaan, setiap perusahaan telah memasang targetnya masing-masing, hal ini dilakukan agar tercapainya tujuan perusahaan dengan strategi yang tepat dapat berjalan dengan skenario manajemen perusahaan.

Perusahaan harus bisa memaksimalkan serta mengelola SDM dengan baik agar tujuan perusahaan yang telah ditetapkan tercapai. Sumber daya manusia menjadi faktor penting organisasi, hal tersebut dibebakan karna SDM menjadi elemen utama operasional perusahaan setiap hari. Meningkatkan kualitas juga salah satu faktor untuk menjadikan karyawan lebih terarah dalam mencapai tujuan organisasi. Problematika mengenai karyawan merupakan masalah yang harus selalu diperhatikan oleh organisasi karena kualitas dan kuantitas dapat terpengaruh sehingga dapat menghadapi persaingan zaman. Maka dari itu, agar tujuan organisasi tercapai dengan baik maka sumber daya manusia yang berkualitas sangat dibutuhkan. Jika karyawan di suatu organisasi mempunyai kemampuan mengembangkan inovasi, kreatif dan memiliki motivasi diri yang tinggi dapat menjadikan kinerja karyawan yang baik. Agar ekstensi diri tetap terjaga maka setiap individu akan mengalami stress kerja terutama bagi individu yang kurang dapat menyesuakan diri dengan perkembangan tersebut.

Perusahaan kini dihadapkan banyak permasalahan yang timbul disebabkan oleh intern serta ekstern perusahaan, sebab itu manajemen harus lebih intens serta detail dalam mengawasi setiap pekerjaan serta setiap bagian perusahaan agar terlaksana sesuai SOP perusahaan. Kini perusahaan harus berhati-hati dalam mengambil langkah kebijakan, sebab perusahaan harus selalu melakukan evaluasi terhadap intern organisasi agar selalu kondusif, pengoptimalan SDM dengan baik serta produktif akan memberikan dampak baik untuk perusahaan.

Perkembangan bisnis diberbagai sektor kini telah memasuki babak baru, kita bisa melihat banyaknya organisasi ataupun perusahaan yang baru dibangun oleh para pebisnis. Hal ini menjadi salah satu bentuk semakin berkembangnya dunia ekonomi Indonesia. Sekarang telah memasuki era dimana semua pribadi bisa menjadi seorang pebisnis, banyak kesempatan yang dapat dilakukan oleh para pebisnis baru, dengan modal ilmu pengetahuan serta modal keungan untuk membangun perusahaan sudah dapat menjadi seorang pebisnis yang handal dibidangnya masing-masing. 
Sebagai perusahaan yang maju haruslah memiliki potensi SDM yang mampu memberikan kontribusi maksimal, sehingga dalam kondisi apapun perusahaan mampu untuk beradaptasi pada segala risiko yang terjadi dikemudian hari.

\section{KERANGKA KONSEPTUAL}

Adapun kerangka konseptual riset ini sebagai berikut :

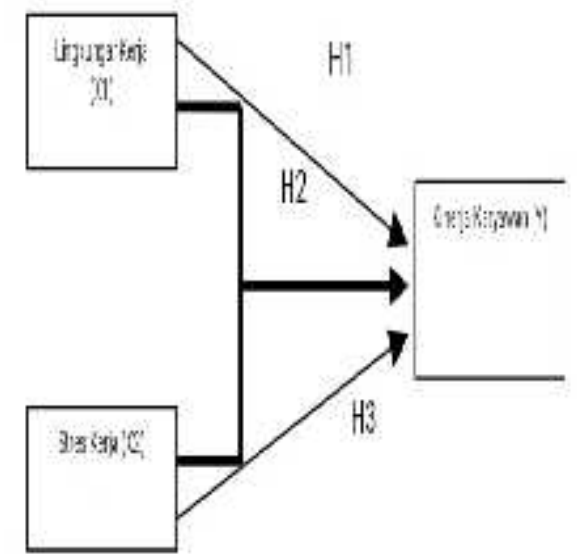

\section{METODE}

Pendekatan riset ini memakai pendekatan kuantitatif deskriptif. Adapun populasi riset ini yakni seluruh karyawan PT. Dwi Mulya Jaya Mojokerto sejumlah 76 karyawan. Teknik sampel memakai sampling jenuh.

HASIL \& PEMBAHASAN

Tabel 1

Uji reliabilitas lingkungan kerja

\begin{tabular}{|c|c|c|c|}
\hline lient & $\begin{array}{l}\text { Crothbech } \\
\text { Aspha }\end{array}$ & $\begin{array}{l}\text { Nigi } \\
\text { Kititis }\end{array}$ & Keterangar \\
\hline Perelamant & 0,828 & 0,6 & Relliabel \\
\hline Partukiaran Udara & 0,710 & 0,6 & Reliabel \\
\hline Ketersihan & 0,866 & 0,6 & Relliabel \\
\hline Pyvamban & $(7,7) 8$ & 0,6 & Relliabel \\
\hline Kebisingan & 6,778 & 0,6 & Reliabel \\
\hline Keamınar & 6,711 & 0,6 & Reliabel \\
\hline
\end{tabular}


Tabel 2

Uji reliabilitas

Hassil Pengyj|ar Relibili.as

Varlabel Stres Keria

\begin{tabular}{|c|c|c|c|}
\hline len & $\begin{array}{l}\text { Cronthech } \\
\text { Applie }\end{array}$ & $\begin{array}{l}\text { Nigi } \\
\text { Kints }\end{array}$ & Keterangan \\
\hline Gepala Fisklologls & 6890 & 0,6 & 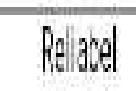 \\
\hline 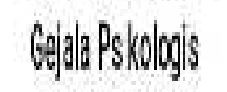 & 0787 & 06 & Retigeal \\
\hline 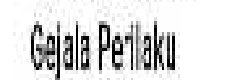 & 1800 & d. & Reigrel \\
\hline
\end{tabular}

Tabel 3

Uji reliabilitas

\begin{tabular}{|c|c|c|c|}
\hline \multicolumn{4}{|c|}{ 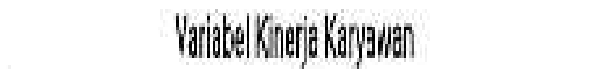 } \\
\hline Iten & $\begin{array}{l}\text { Utrortlach } \\
\text { Apha }\end{array}$ & $\begin{array}{l}\text { Nib } \\
\text { Kitis }\end{array}$ & Ketelargas \\
\hline 《allitha & 1324 & di & ritike \\
\hline Larititas & 1,793 & $0, j$ & Pilite \\
\hline Letepatarn liatch & 1,30 & 0,0 & tititele \\
\hline 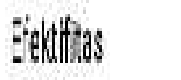 & 1,300 & $0, j$ & Jilitele \\
\hline (emaraditien & 1,711 & $0, j$ & Silitele \\
\hline
\end{tabular}

Dijelaskan uji reliabilitas semua item terbukti reliabel, sebab diperoleh nilai > ,06 
Uji Normalitas

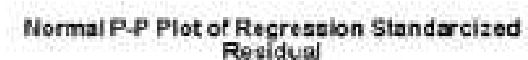

Rosidual

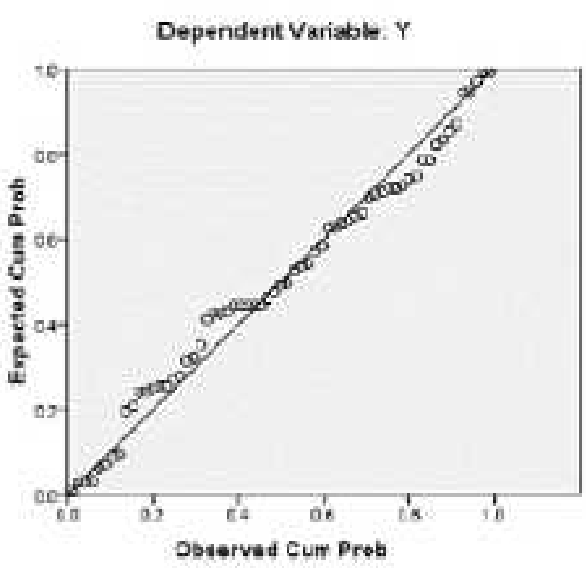

Dijelaskan serta dibuktikan data uji normalitas, titik mengikuti garis, sehingga terbukti data berdistribusi nurmal.

Tabel 4.

Uji multikolineritas

Hasil Uji Mutikolineritas

\begin{tabular}{|c|c|c|c|}
\hline \multirow[t]{2}{*}{ Variabel } & \multicolumn{2}{|c|}{$\begin{array}{l}\text { Collinearity } \\
\text { Statistics }\end{array}$} & \multirow[t]{2}{*}{ Ket. } \\
\hline & Tolerance & $V / F$ & \\
\hline $\begin{array}{l}\text { Linckuncankela } \\
(\lambda i)\end{array}$ & 0,333 & 2,535 & $\begin{array}{l}\text { Non } \\
\text { Nultikolinise }\end{array}$ \\
\hline Stes Kejaix) & 0,333 & 2,535 & ritas \\
\hline
\end{tabular}

Dijelaskan data diperoleh VIF X1 2,535 serta X2 2,535. Terbukti data terbebas dari multikolineritas. 
Uji heteroskedastisitas

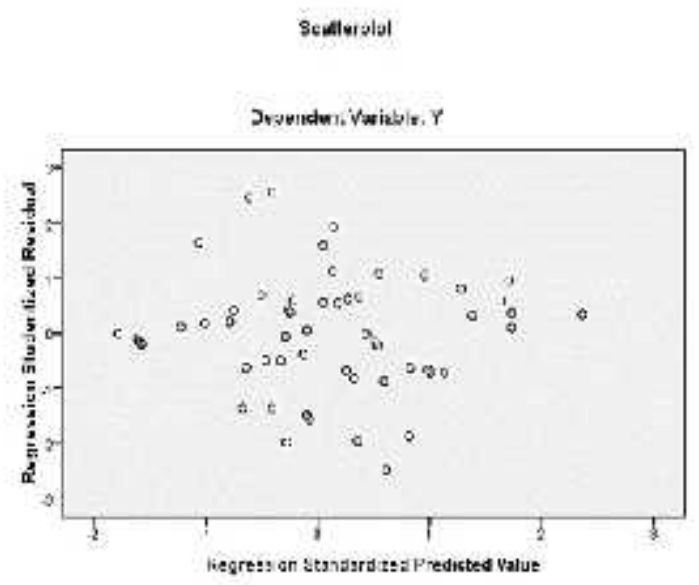

Dijelaskan gambar diatas titik menyebar secara acak serta tidak membentuk pola tertentu, disimpulkan data terbebas dari heteroskedastisitas.

Tabel 5

Uji Autokorelasi

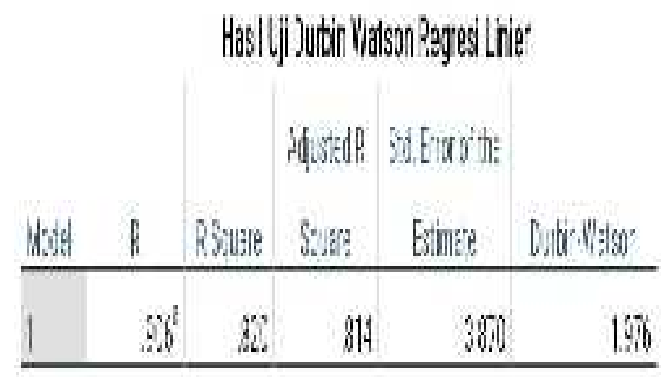

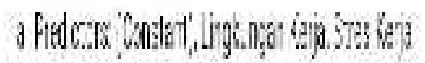

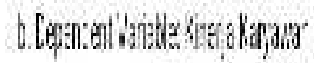

Dijelaskan uji autokorelasi data didapatkan DW 1,976, disimpulkan serta terbukti data terbebas dari autokorelasi. 
Tabel 6

Uji regresi linier berganda

\begin{tabular}{|c|c|c|c|c|c|}
\hline$\rightarrow$ & Jnisterderch & d Deff tients & $\begin{array}{l}\text { Sta:dedolizet } \\
\text { Cxeffisents }\end{array}$ & & - \\
\hline dast? & 3 & ydd terx & sto & 1 & ij \\
\hline 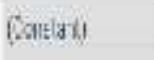 & 1333 & 29 & & $3 \cdot 0$ & .30 \\
\hline Lns:nzenKe, 3 & 134. & 3. & 5.52 & 433: & . \\
\hline Slueskleyo & $1: 65$ & $23 i$ & .738 & is 15 & $\therefore 3$ \\
\hline
\end{tabular}

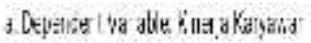

Tabel 7

Uji-t

Hasil Ujit Secrra Parsial

\begin{tabular}{|l|l|l|l|}
\hline \multicolumn{1}{|c|}{ Variabel } & thiwa. & Sig. & Keterangan \\
\hline Lingkungan Kerja $\left(X_{1}\right)$ & 4.338 & .010 & Signitikan \\
\hline Stres Kerja $\left(X_{2}\right)$ & 4.916 & .023 & Signifikan \\
\hline
\end{tabular}

Dijelaskan uji-secara terpisah didapatkan hasil thitung lingkungan kerja 4,338 serta sig. , $010<, 05$. Artinya variabel bebas terbukti adanya pengaruh terhadap variabel terikat.

Uji-secara terpisah didapatkan hasil thitung stress kerja 4,916 serta sig. ,023<,05. Artinya variabel bebas terbukti adanya pengaruh terhadap variabel terikat.

Tabel 8

Uji-f

Fasi enalisis regresi secara siruiten

\begin{tabular}{|c|c|c|}
\hline Variabel & Fitury & Sig. \\
\hline jndkungan Kerja $\left(X_{1}\right)$ & & \\
\hline Stres Keja $\left(X_{0}\right)$ & 37.75 & $.00^{t}$ \\
\hline
\end{tabular}


Dijelaskan hasil uji-f hitung didapatkan 37,075 serta sig., $000<, 05$. Artinya secara bersamaan ada pengaruh variabel bebas terhadap variabel terikat.

\section{PEMBAHASAN}

Dijelaskan hasil yang telah dilakukan oleh penulis bahwa uji-t memperoleh nilai 4,338 serta sig., $010<, 05$. Artinya variabel bebas terbukti adanya pengaruh terhadap variabel terikat.

Dijelaskan serta dibuktikan Uji-secara terpisah didapatkan hasil thitung stress kerja 4,916 serta sig. ,023 <, 05. Artinya variabel bebas terbukti adanya pengaruh terhadap variabel terikat.

Dijelaskan serta dibuktikan uji-f hitung didapatkan 37,075 serta sig. ,000<,05. Artinya secara bersamaan ada pengaruh variabel bebas terhadap variabel terikat.

\section{SIMPULAN}

Sesuai hasil riset, dapat diambil simpulan bahwa uji-t memperoleh nilai 4,338 serta sig., $010<, 05$. Artinya variabel bebas terbukti adanya pengaruh terhadap variabel terikat.

Disimpulkan serta dibuktikan Uji-secara terpisah didapatkan hasil thitung stress kerja 4,916 serta sig., $023<, 05$. Artinya variabel bebas terbukti adanya pengaruh terhadap variabel terikat.

Disimpulkan serta dibuktikan uji-f hitung didapatkan 37,075 serta sig. ,000<,05. Artinya secara bersamaan ada pengaruh variabel bebas terhadap variabel terikat.

\section{IMPLIKASI}

Sesuai dengan hasil riset ini, telah menghasilkan suatu temuan terbaru bagi perusahaan, temuan ini diharapkan bisa menjadi bahan evaluasi yang dapat digunakan oleh perusahaan PT. Dwi Mulya Jaya Mojokerto untuk mengambil suatu kebijakan mengenai SDM perusahaan yang dapat memberikan dampak positif dalam melaksanakan strategi perusahaan.

\section{KETERBATASAN PENELITIAN}

Dijelaskan pada riset ini penulis telah melakukan pengujian variabel, penulis melaksanakan riset dengan waktu yang sangat terbatas, sampel pada riset ini juga dibatasi yakni perusahaan PT. Dwi Mulya Jaya Mojokerto. 


\section{DAFTAR RUJUKAN}

Anwar P. (2002). Insentif dan Motivasi Instansi Negara. Jakarta. Rajawali Pers.

Sunyoto Danang. (2016). Sumber Daya Manusia. Jakarta. CAPS.

Livanda Wenly Umboh, Bernhard Tewal, Adolvina, 2016, Pengaruh Disiplin, Pelatihan, Pengalaman, dan Lingkungan Kerja Terhadap Prestasi Kerja Karyawan. Manado PT. Enseval Putera Mega Trading. Jurnal EMBA. Vol. 4 No.1 Maret 2016, Hal 566-574.

Militya Ch. Takasenseran, Silvya L. Mandey, Christoffel Kojo, 2014, Pengaruh Lingkungan Kerja, Komunikasi dan Stres Kerja Terhadap Kinerja Pegawai pada Dinas Pendidikan dan Kebudayaan Provinsi Sulut. Jurnal EMBA. Vol.2 No.3 September 2014, Hal. 1726-1736.

Mangkunegara, AA Prabu. (2006). Manajemen Sumber Daya Manusia. Bandung.Remaja Rosdakarya.

Nitisemito, Alex S. (2000). Manajemen Pemasaran. Jakarta, Ghalia Indonesia. 